\title{
Ballistic Impact Response of Woven Hybrid Coir/Kevlar Laminated Composites
}

\author{
A.R Azrin Hani ${ }^{1,2, *}$, N.S Azman ${ }^{1}$, R. Ahmad $^{3}, M$. Mariatti $^{4}, M . N$ Roslan $^{1,2}$, and N. Marsi ${ }^{1,2}$ \\ ${ }^{1}$ Faculty of Engineering Technology, University Tun Hussein Onn Malaysia, 86400 Parit Raja, Batu \\ Pahat, Johor, Malaysia. \\ ${ }^{2}$ Advanced Technology Centre, Faculty of Engineering Technology, University Tun Hussein Onn \\ Malaysia, 86400 Parit Raja, Batu Pahat, Johor, Malaysia. \\ ${ }^{3}$ School of Mechanical Engineering, Engineering Campus, Universiti Sains Malaysia, 14300 Nibong \\ Tebal, Pulau Pinang, Malaysia. \\ ${ }^{4}$ School of Materials and Mineral Resources Engineering, Engineering Campus, Universiti Sains \\ Malaysia, 14300 Nibong Tebal, Pulau Pinang, Malaysia.
}

\begin{abstract}
The effects of different laminated hybrid composites stacking configuration subjected to ballistic impact were investigated. The hybrid composites consist of woven coir (C) and woven Kevlar (K) layers laminated together. The samples of woven coir were prepared using handloom device. The composites were produced by stacking the laminated woven coir and Kevlar alternately with the presence of the binder. The samples were tested under ballistic impact with different stacking configuration. The results obtained had successfully achieved the National Institute of Justice (NIJ) standard level IIA with energy absorption of $435.6 \mathrm{~kJ}$ and $412.2 \mathrm{~kJ}$ under the projectile speed of between $330 \mathrm{~m} / \mathrm{s}$ and $321 \mathrm{~m} / \mathrm{s}$ respectively. Samples that having Kevlar layer at the front face and woven coir layer as back face achieved partial penetration during projectile impact. This orientation is proven to have good impact energy absorption and able to stop projectile at the second panel of the composites.
\end{abstract}

\section{Introduction}

Body armour is a protective garment used to protect the body from any projectile penetration. According to Cavallaro [1], the earliest invention that used body armour concept is using animal skin as well as Natural Fibre (NF) made from thatch, cotton, and silk that is woven to make a protective garment. The concept is then evolved using a more advanced material such as iron, copper, steel that made into the plate to protect the body. Hence, the fibres being used need to be as strong as it could be. Today, Synthetic Fibre (SF) has manipulated the production of body armour with its good mechanical properties. The most commonly used SF in body armor is the high performances fibre such as Kevlar and Twaron from aramid family, Ultra High Molecular Weight Polyethylene (UHMPE) and nylon.

\footnotetext{
*Corresponding author: azrin@uthm.edu.my
} 
The advanced research was carried out to improve the quality of body armor performances and trying to replace the SF used with NF that has a great potential, equal to the SF. Based on the report by Wambua [2], NFs have the economical value since it is from natural resources, renewable, biodegradable, recyclable and have low health risk when inhaled compared to GF and SF. However, the NF contain cellulose, hemicelluloses, pectins and lignin and are rich in hydroxyl groups which making the characteristics of NF hydrophobicity. With this character, it reduces the interfacial adhesion of the NF. Cellulose is often found as a relatively high modulus, fibril component, of many naturally occurring composites, such as wood, where it is found in association with lignin [3] According to the research of Yousif et al. [4] highlighted that this distinct value is due to its weakness in the interfacial adhesion of NFs with synthetic matrices. So in order to improve this issue, surface modification needs to be done.

Meon et. al [5] have conducted research on the potential Kenaf fibre with the treatment of $\mathrm{NaOH}$. This research was inspired by the previous research done by Mwaikambo and Ansell [6] where they treated NFs such as hemp, sisal, jute and kapok fibres with various concentration of caustic soda. Their aim was to remove the surface impurities in order to enhance the surface adhesion characteristic. With the treatment of alkali, the NF tends to have a better thermo physical properties. It is proven that $\mathrm{NaOH}$ improves the interlocking and chemical bonding between the fibre and matrices which resulting in a better mechanical property.

The effects of different laminated stacking configuration subjected to ballistic impact were investigated. The composites consist of woven $\operatorname{Kevlar}(\mathrm{K})$ and woven treated coconut coir (C). A follow-up investigations were also done to assess blunt trauma effect.

\section{Experimental Method}

\subsection{Material}

Plain weave Kevlar 29 was used in this research. It was taken from China Beihai Fiberglass Co. Ltd., China. The yarn size is 1100 dtex whereas the fabric weight is $200 \mathrm{~g} / \mathrm{m}^{2}$. The coconut coir yarn used in this experiment was provided by Btex Engineering Ltd., India. The yarns were weaved into the plain woven structure formed into composite panel and tested it under ballistic test. The density of coir as stated by Akil et.al. [3] is within the range of $1.15-1.46 \mathrm{~g} / \mathrm{cm}^{3}$.

The matrix used was epoxy DER 332 of density $1.16 \mathrm{~g} / \mathrm{mL}$. Jeffamine D-230 hardener of density $0.948 \mathrm{~g} / \mathrm{mL}$ was used as curing agent. Both the resin and hardener were supplied by Penchem Technologies Sdn. Bhd. Malaysia.

\subsection{Sample Preparation}

The process started with the preparation of dry fabric/mat of plain woven coir. Woven coir as a composite reinforcement was produced with a self-designed handloom [7]. The woven fabrics were then soaked as part of the treatment process in sodium hydroxide $(\mathrm{NaOH})$ solutions of concentrations $6 \%$. The manufacture of structural composites involved the compression moulding method. Fibre-matrix ratios were fixed at $3: 7$ by weight percentage. The mould was closed and placed in a pressing device overnight for curing. The composites were then analysed in terms of thickness, and weight. The composites were labelled and stacked into one panel which consists of three same composites. The stacking configuration was varied to investigate its effect on ballistic impact. 


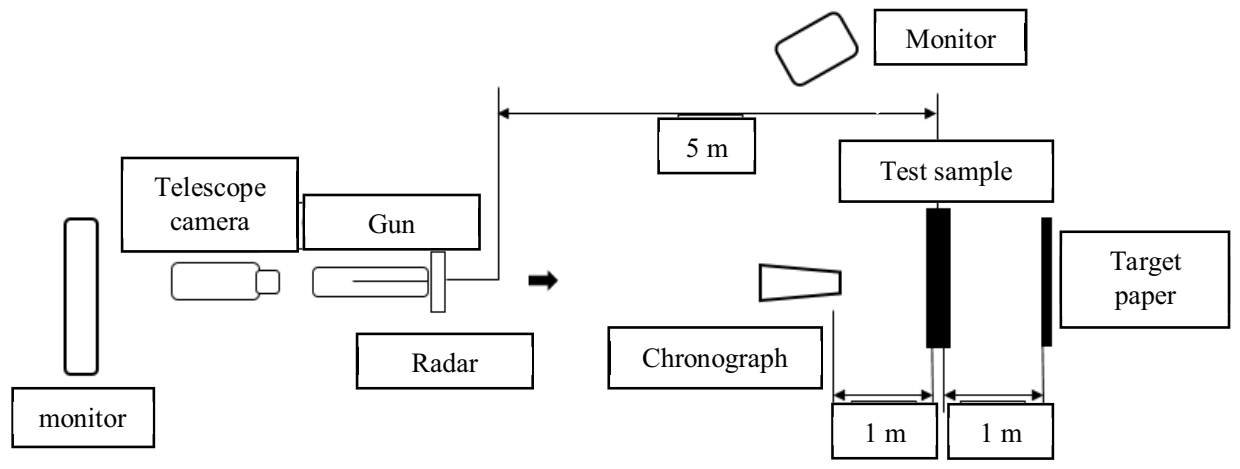

Fig. 1. Schematic diagram of testing apparatus in STRIDE, Batu Arang.

\subsection{Testing Method}

Samples were tested at Science and Technology Research Institute of Defence (STRIDE), Batu Arang, Selangor for high-velocity impact test. The assessments involve the determination of ballistic limit, damage mode, and blunt trauma deformation. The tests were performed guided by NIJ Standard 0101.04 [8] level IIA with 9 mm calibre FMJ RN $8.0 \mathrm{~g}$. Figure 1 shows the schematic diagram of the testing apparatus. The samples to be tested were cut into $310 \times 205 \mathrm{~mm}$ dimensions, and thickness within the range of $7 \mathrm{~mm}$ to 9 $\mathrm{mm}$ for one composite panel (each containing 4 layers of woven laminated coir/ Kevlar). It was then stacked into 3 sets of panel (12 layers of woven laminated coir/Kevlar). The ballistic impact was conducted using high-velocity impact gun muzzle.

\section{Results and Discussion}

\subsection{Ballistic Impact Response}

Table 1 shows the results of ballistic impact response of composites composed of different stacking sequence. The first shot was using only 2 panels. The top surface of the panel is Kevlar while the back surface is woven coir. The results were a complete penetration. The velocity used to be $368 \mathrm{~m} / \mathrm{s}$ which categorized under NIJ-Standard level II. However the panel is too thin and the velocity of the projectile was too high that the panel could not stop the projectiles. The structure of woven coir which placed as the back face of the panel was dispersed and break into small pieces. This was due to the structure of the panel where the composites were not properly dried due to the environmental factor and mould used. However, the semi-dried panel was observed to be good in energy absorption. This was proven by the 3, 4 and 5 shots in this test.

For the second shot, another panel was added. Hence given a total of 3 panels in a sample with a total weight and thickness of $1.89 \mathrm{~kg}$ and $25.07 \mathrm{~mm}$ respectively. The projectile speed was recorded as $378 \mathrm{~m} / \mathrm{s}$ which satisfied threat level II. The stacking orientation for the panel was KKCC-KKCC-CCKK where Kevlar was placed on the front and back face of the panel. However, complete penetration occurred which makes the researcher decided to reduce the speed of the projectile. On the third shot, the striking velocity or the impact velocity was reduced to $330 \mathrm{~m} / \mathrm{s}$. The velocity of the projectiles was reduced by decreasing the propellant charged weight of total $350 \mathrm{mg}$. The more charged weight used, the higher the velocity of the projectile. The stacking orientation of the panel 
for this shot was KKCC-KKCC-KKCC with Kevlar on the front face, and woven coir on the back face of the panel. The energy absorption for this shot was $438 \mathrm{~kJ}$. This panel achieved the desired result with partial penetration condition. Stacking sequence or orientation was believed to be the main factor that can arrest the projectile. The placement of Kevlar on the front face of every panel slowed down the velocity of the projectiles while the presence of the woven coir at the back absorbed the energy released. It was observed that the fracture mode on Kevlar layer was small and greater delamination occurred. Delamination is believed due to the dissipation of energy at Kevlar layer during projectile impact. Aktas et. al [9] clearly stated that in hybrid composites, woven structure placed on the outer layer gave a better result. This works well for coconut coir that was weaved into the plain woven structure and proven to withstand high impact energy.

Table 1. Ballistic test results of woven coir/Kevlar composites.

\begin{tabular}{|c|c|c|c|c|c|c|}
\hline $\begin{array}{c}\text { Shots } \\
\text { number }\end{array}$ & $\begin{array}{c}\text { Stacking } \\
\text { orientation }\end{array}$ & $\begin{array}{c}\text { Striking } \\
\text { Velocity 1 } \\
(\mathbf{m} / \mathbf{s})\end{array}$ & $\begin{array}{c}\text { Striking } \\
\text { Velocity 2 } \\
(\mathbf{m} / \mathbf{s})\end{array}$ & $\begin{array}{c}\text { Striking } \\
\text { Energy (kJ) }\end{array}$ & \multicolumn{2}{|c|}{$\begin{array}{c}\text { Penetration } \\
\text { (CP/PP) }\end{array}$} \\
\hline 1 & $\begin{array}{c}2 \text { panels } \\
* \mathrm{KC}+\mathrm{KC}\end{array}$ & 369.8 & 368.0 & 544.0 & $\sqrt{ }$ & \\
\hline 2 & $\begin{array}{c}3 \text { panels } \\
* \mathrm{KC}+\mathrm{KC}+ \\
\mathrm{CK}\end{array}$ & 375.8 & 378.0 & 574.0 & $\sqrt{ }$ & \\
\hline 3 & $\begin{array}{c}3 \text { panels } \\
* \mathrm{KC}+\mathrm{KC}+ \\
\mathrm{KC}\end{array}$ & 328.5 & 330.0 & 438.0 & & $\sqrt{ }$ \\
\hline 4 & $\begin{array}{c}3 \text { panels } \\
* \mathrm{KC}+\mathrm{KC}+ \\
\mathrm{KC}\end{array}$ & 321.5 & 321.0 & 414.0 & & $\sqrt{ }$ \\
\hline 5 & $\begin{array}{c}3 \text { panels } \\
* \mathrm{KC}+\mathrm{KC}+ \\
\mathrm{CK}\end{array}$ & 348.7 & 348.0 & 487.0 & & $\sqrt{ }$ \\
\hline 6 & $\begin{array}{c}3 \text { panels } \\
* \mathrm{KC}+\mathrm{KC}+ \\
\mathrm{CK}\end{array}$ & 343.8 & 343.0 & 473.0 & $\sqrt{ }$ & \\
\hline
\end{tabular}

*Each panel consist of 2 layers of woven Kevlar $(\mathrm{K})$ and 2 layers of woven coir $(\mathrm{C})$.

$* \mathrm{CP}=$ complete penetration, $\mathrm{PP}=$ partial penetration

From the fourth shots, the same orientation used was gave a similar trend with the previous shot (shot 3 ). The striking velocity recorded was $321 \mathrm{~m} / \mathrm{s}$ and partial penetration was achieved with $414 \mathrm{~kJ}$ of energy being absorbed by the composites. By maintaining the type of stacking configuration and the range of projectile striking velocity in shot number 5 , it also produced the same ballistic response with the previous shot number 3 and 4 . Partial penetration occurred. With this trend, it is proven that this orientation exhibited better ballistic energy absorption. However, an attempt to increase the projectile velocity will need modification on the panels thickness and orientation. With the higher projectile striking velocity (as referring to shot number 6 from Table 1), the panel shows complete penetration. It can be concluded that the hybrid of woven coir and Kevlar laminated composites has high potential as applications for high protective materials at lower cost. 


\subsection{Blunt Trauma}

Blunt trauma test was done using composite panel where the stacking orientation was the same as the successful panel with partial penetration in ballistic test in the previous section. The backing material was Roma Plastilina with the temperature of $40^{\circ} \mathrm{C}$. The results show that the projectile was successfully stopped and embedded inside the panel. Blunt trauma depth of penetration was measured using Vernier Calliper. The depth of penetration is called as back face signature (BFS).

A shot was launched and the results of BFS for blunt trauma assessment are tabulated in Table 2. From Table 2 it is obvious that area of the deformation was $21.16 \mathrm{~cm}^{2}$. The bigger area represents the energy being dissipated in a wider area to stop the projectiles. The depth of penetration or so called BFS also shows a very good result with the length of $6.79 \mathrm{~mm}$, whereas the limit given by standard in designing armor panel must be less than $24 \mathrm{~mm}$.

Table 2. Blunt trauma assessment result.

\begin{tabular}{|c|c|c|c|c|c|}
\hline \multirow{2}{*}{ Orientation } & \multirow{2}{*}{$\begin{array}{c}\text { Length } \\
\text { horizontal } x, \\
(\mathrm{~cm})\end{array}$} & \multirow{2}{*}{$\begin{array}{l}\text { Length } \\
\text { vertical y, } \\
\text { (cm) }\end{array}$} & \multirow{2}{*}{$\begin{array}{c}\text { Area of } \\
\text { Deformation } \\
\left(\mathrm{cm}^{2}\right)\end{array}$} & \multicolumn{2}{|c|}{ Penetration } \\
\hline & & & & $\mathbf{C P} / \mathbf{P P}$ & $\begin{array}{l}\text { BFS } \\
(\mathrm{mm})\end{array}$ \\
\hline $\begin{array}{c}3 \text { panels: } \\
* \mathrm{KW}+\mathrm{KW}+\mathrm{KW}\end{array}$ & 4.6 & 4.6 & 21.16 & PP & 6.79 \\
\hline
\end{tabular}

\subsection{Damage Assessment}

The partial penetration (PP) samples are referring to shot number 3, 4 and 5 as detailed in Table 1. Damage is obviously seen on the back face of the panel. For shot number 3, the damage mode on the first panel was small. This was expected due to the impact of the projectile which was still in high velocity. When the projectile reaches the second panel, the damage mode was huge. The bigger the damage mode the higher the energy absorption. At this stage, the projectile stop and the woven coir were broken into pieces due to high impact. The projectiles were found crumpled right at the very end of the second panel on the structure of woven coir. Even though it stops on the second panel, there was still huge damage done on the third panel. The layer of Kevlar on the third panel does not penetrate through, however, the woven coir structure ruptured on the outside.

The similar damage mode can be seen for shot number 4 . The similarity might be due to the same orientation used where the Kevlar as the front face and woven coir as the back face of the panel. From the results and observation, this consistency proved that this structure was strong enough to stop the projectiles. The damage on the first panel (as predicted) was small, both for Kevlar and woven coir. Whereas for the second panel, larger damage mode can be seen on the woven coir but not on the Kevlar structure. Based on this observation, woven coir is proven to have a better energy absorption. It has similar damage mode with shot number 3. On the third panel, Kevlar layer does not break, but the energy was absorbed by the woven coir on the back face of the panel.

A different condition was observed for shot number 5. The energy absorbed by the panel was $487 \mathrm{~kJ}$, which was considered high. The plate achieved the condition of partial penetration but Kevlar which was placed on the back face of the panel peeled off from the panel as clearly seen in Table 3. Kevlar was expected not to be properly stuck to the woven coir during the fabrication which causing it to be separated when high impact applied. The damage mode on the third panel of the woven structure was the largest among the 3 shots of PP condition. The higher velocity of bullet resulting in this condition. 


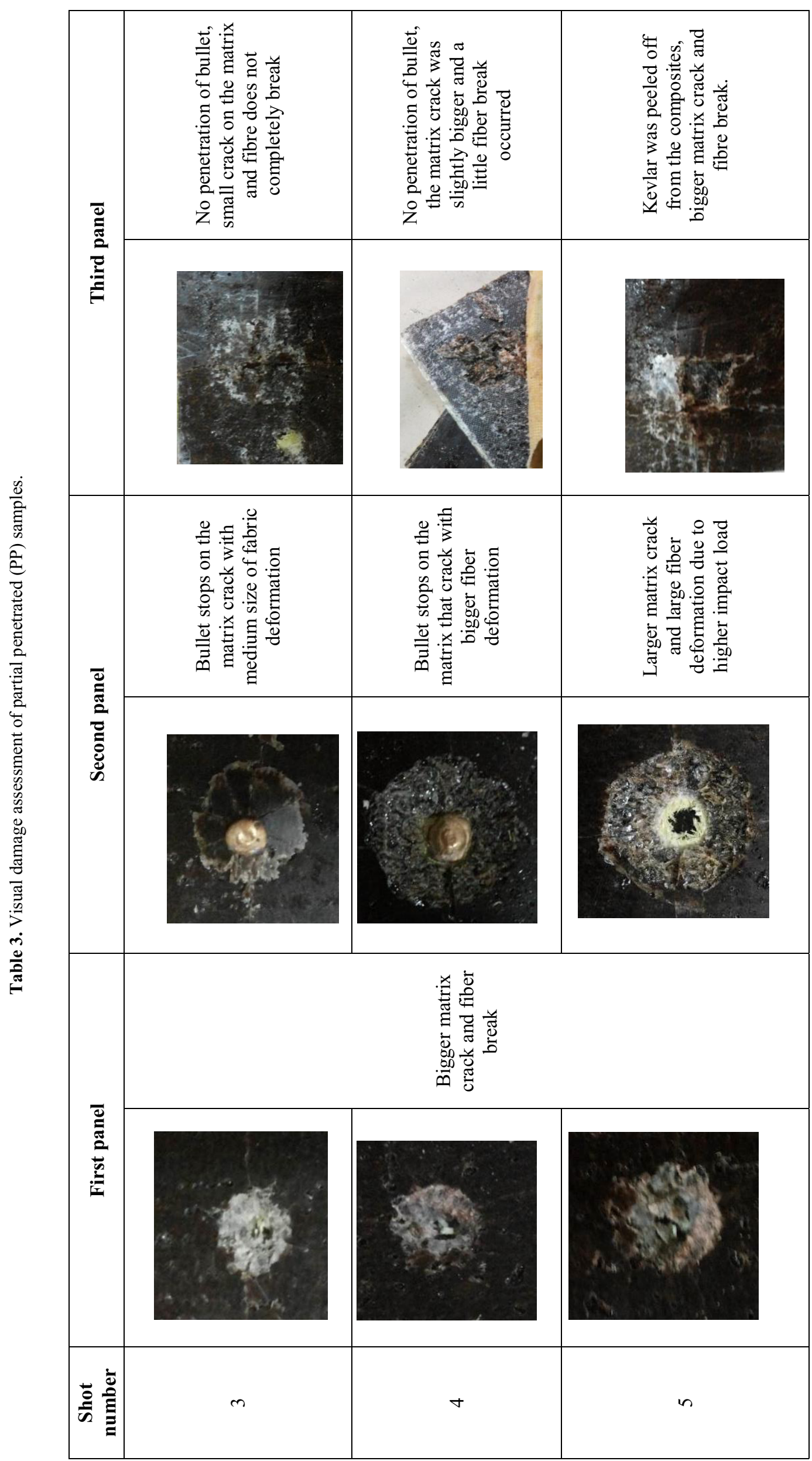




\section{Conclusion}

It can be concluded that the generated information from this research has achieved the objective which is to investigate the effects of different laminated coir/Kevlar hybrid composites stacking configuration subjected to ballistic impact. The best stacking sequence would be KKCC-KKCC-KKCC with the ballistic limit of $348 \mathrm{~m} / \mathrm{s}$. The same orientation successfully undertook blunt trauma test with BFS depth of $6.79 \mathrm{~mm}$. This study has high impact in reducing the usage of the expensive and non-biodegradable product, Kevlar to more than half of the normal usage in the production of armour panel.

The authors gratefully acknowledge Advanced Technology Centre (ATC), Faculty of Engineering Technology, Universiti Tun Hussein Onn Malaysia (UTHM) for supporting this research. The authors also would like to express sincere appreciation to the staffs of Science and Technology Research Institute of Defence (STRIDE) for the generous assistance.

\section{References}

1. P.V. Cavallaro, Soft body armor: An overview of materials, manufacturing, testing and ballistic impact dynamics (Naval Undersea Warfare Center Division, NUWC-NPT Technical Report, 2011)

2. P. Wambua, J. Ivens, I. Verpoest, Compos. Sci. Technol., 63(9), 1259 (2003)

3. H.M. Akil, M.F. Omar, A.A.M. Mazuki, S. Safiee, Z.A.M. Ishak, A. Abu Bakar, Mater. Design, 32, 4107 (2011)

4. B.F. Yousif, A. Shalwan, C.W. Chin, K.C. Ming, Mater. Design, 40, 378 (2012)

5. M.S. Meon, M.F. Othman, H. Husain, M.F. Remeli, M.S.M. Syawal, Procedia Engineering, 41, 1587 (2012)

6. L.Y. Mwaikambo, M.P.Ansell, Macromol. Mater. Eng., 272(1), 108 (1999)

7. A.R. Azrin Hani, M.F. Shaari, N.S. Mohd Radzuan, M.S. Hashim, R. Ahmad, M. Mariatti, The International Journal of Automotive Engineering, 8, 1197 (2013)

8. NIJ Standard-0101.04, Ballistic resistance of personal body armor (US Dept. Just. Washington, DC, 2001)

9. Aktas, M. Aktas, F. Turan, Compos. Struct,, 103, 119 (2013) 